\title{
The first site of recurrence after complete resection in non-small-cell carcinoma of the lung
}

\author{
Comparison between $p N O$ disease and $p N 2$ disease
}

In the present study, we assessed whether the pattern of postoperative recurrence of non-small-cell lung cancer differed between patients with pathologic N0 disease and those with pathologic N2 disease. We reviewed 231 patients with pathologic N0 disease and 63 with pathologic N2 disease, who had undergone a complete resection from 1980 to 1990 , and investigated the first recurrence sites. Seventy-two patients with pathologic N0 disease and 52 with pathologic N2 disease were found to have had postoperative recurrence. Both pathologic N0 disease and pathologic N2 disease recur frequently in distant organs, and the ratio of distant metastasis to local recurrence did not differ between the two diseases. The brain, lung, and bone were the common initial metastatic sites in both pathologic N0 disease and pathologic $\mathrm{N} 2$ disease. The brain was the most frequent site of distant metastasis in patients with pathologic NO disease, whereas, on the other hand, pulmonary metastasis was observed more frequently than brain metastasis in those with pathologic N2 disease. Despite histologic types, the presence of different patterns of initial metastatic sites between pathologic N0 and pathologic N2 diseases was observed. Our results suggest that the sites of metastasis after resection depend largely on such anatomic factors as drainage routes. Namely, in contrast to pathologic N0 disease, pathologic N2 disease has an additional drainage route, which is from the $\mathbf{N} 2$ nodes to the superior vena cava (pulmonary circulation). Therefore, the frequency of pulmonary metastasis may increase in patients with pathologic N2 disease. (J ThORAC CARDiovasc Surg 1994;108:680-3)

Tokujiro Yano, MD, Hideki Yokoyama, MD, Takashi Inoue, MD, Hiroshi Asoh, MD, Kohsuke Tayama, MD, Eiji Takai, MD, and Yukito Ichinose, MD, Fukuoka, Japan

$P$ after resection. ${ }^{1}$ The common sites of distant metastasis are the brain, lung, bone, liver, and adrenal glands. ${ }^{2,3}$

From the Department of Chest Surgery, National Kyushu Cancer Center, Fukuoka, Japan.

Received for publication March 10, 1994.

Accepted for publication June 20, 1994.

Address for reprints: Tokujiro Yano, MD, Department of Chest Surgery, National Kyushu Cancer Center, 3-1-1, Notame, Minami-ku, Fukuoka 815 , Japan.

Copyright $@ 1994$ by Mosby-Year Book, Inc.

$0022-5223 / 94 \$ 3.00+0 \quad 12 / 1 / 58608$
However, it is not known whether the metastatic sites differ according to the initial stages of the disease. Although the biologic characteristics of individual primary tumors may affect the metastatic prevalence, the sites of metastasis are thought to depend largely on such anatomic factors as the routes of draining vessels. In contrast to patients with pathologic NO (pN0) disease, those with $\mathrm{pN} 2$ disease have an additional draining route, which passes from the involved mediastinal lymph nodes to the superior vena cava (pulmonary circulation). This route may increase the frequency of pulmonary metastasis.

In the present study, we reviewed the case histories of 
Table I. Pattern of recurrence in pNO disease versus $p N 2$ disease

\begin{tabular}{lll}
\hline Site & $p N 0$ disease & $p N 2$ disease \\
\hline Distant & $52(70.3 \%)$ & $40(71.4 \%)$ \\
Local & $\frac{22}{74}(29.7 \%)$ & $\frac{16}{56}(28.6 \%)$ \\
Total & & \\
\hline
\end{tabular}

Parentheses indicate percentages of the total number of recurrences.

patients who had recurrent disease after undergoing a complete resection for non-small-cell lung cancer and assessed whether the patterns of postoperative recurrence differ between $\mathrm{pN} 0$ disease and $\mathrm{pN} 2$ disease. Careful evaluation of this information may be useful in performing an efficient postoperative follow-up on such patients.

\section{Patients and methods}

We reviewed the hospital charts of 348 patients with nonsmall-cell carcinoma of the lung that had been completely resected at the National Kyushu Cancer Center during the period from 1980 until 1990. A complete resection consisted of either a lobectomy or pneumonectomy together with a total dissection of the regional lymph nodes (both the ipsilateral hilar and mediastinal systems). In all cases, the resection margin was microscopically proved to be negative for tumor cells. The staging of all patient conditions is reported according to the new International Staging System for Lung Cancer. ${ }^{4}$

Of those 348 patients, 231 had pN0 disease and 63 had pN2 disease. The postoperative follow-up was carried out at our outpatient clinic with patients seen at bimonthly intervals for the first 2 years and then at 3-or 4-month intervals thereafter. A routine evaluation included a physical examination, chest roentgenograms, complete blood counts, and serum chemistry profiles. Although a few patients routinely received screening computed tomographic scans, bone scintiscans, and bronchoscopic examinations once a year, the majority of patients underwent such examinations only when recurrence-related symptoms appeared. However, once any recurrent disease was detected, both whole-body computed tomographic scans and bone scintiscans were routinely performed to search for any other silent lesions. In this study, local recurrence was defined as recurrent disease within the ipsilateral hemithorax other than intrapulmonary lesions, ipsilateral supraclavicular lymph nodes, or mediastinum. As for ipsilateral intrapulmonary lesions, only those including the surgical margin were judged to be local recurrences. All other sites of recurrence were considered to be distant metastases. To exclude any cases of second primary carcinoma of the lung, we diagnosed pulmonary metastasis only when multiple pulmonary nodules were found.

The $\chi^{2}$ test was used to evaluate the significance of the relation between the pathologic nodal status ( $\mathrm{pN} 0$ or pN2) and the sites of postoperative recurrence. Two-sided $p$ less than 0.05 was accepted as significant.

\section{Results}

Of 231 patients with pN0 disease, 72 patients had postoperative recurrences, whereas 52 of 63 patients with
Table II. First sites of distant metastasis in pNO disease versus $p N 2$ disease

\begin{tabular}{lcc}
\hline Site & $p N 0$ disease & $p N 2$ disease \\
\hline Brain & $20(38.5 \%)$ & $6(15.0 \%)$ \\
Lung & $10(19.2 \%)$ & $12(30.0 \%)$ \\
Bone & $12(23.1 \%)$ & $12(30.0 \%)$ \\
Liver & $2(3.8 \%)$ & $3(7.5 \%)$ \\
Others & $\underline{8}(15.4 \%)$ & $\underline{7}(17.5 \%)$ \\
Total & 52 & 40 \\
\hline
\end{tabular}

Parentheses indicate percentages of the total number of recurrences.

pN2 disease did. In 2 of 72 patients with recurrent pN0 disease and 4 of 52 patients with recurrent $\mathrm{pN} 2$ disease, two distinct lesions were found at the same time. Therefore, 124 patients with postoperative recurrences had 130 lesions as the first sites of recurrence to be assessed. As shown in Table I, both pN0 disease and pN2 disease recurred frequently in distant organs, but the ratio of distant metastasis to local recurrence did not differ between the two diseases.

Table II shows the first sites of distant metastasis according to the pathologic nodal status. The brain, lung, and bone were the common metastatic sites both in patients with $\mathrm{pN} 0$ disease and in those with $\mathrm{pN} 2$ disease. Of those, the brain was the most frequent site of distant metastasis in patients with $\mathrm{pN} 0$ disease. In contrast, pulmonary metastasis was more prevalent than brain metastasis in patients with $\mathrm{pN} 2$ disease. The difference in the pattern of distant metastasis between pN0 disease and pN2 disease was significant $(p=0.044)$. Especially in patients with pT1 N2 disease, more than half $(55.6 \%)$ of the first distant metastatic sites were found to be in the lungs. On the other hand, in those with pT1 N0 disease, less than $10 \%$ of the sites were in the lungs (data not shown).

Table III shows the prevalence of the first sites of distant metastasis according to histologic types. In both squamous cell carcinomas and nonsquamous ones (54 adenocarcinomas, 5 adenosquamous cell carcinomas, and 5 large cell carcinomas), pulmonary metastasis was prevalent in patients with $\mathrm{pN} 2$ disease and brain metastasis in patients with $\mathrm{pN} 0$ disease.

\section{Discussion}

Little information has been published comparing the patterns of recurrence after complete resection for nonsmall-cell lung cancer in patients with pN0 disease versus pN2 disease. Most previous studies compared the patterns of recurrence in $\mathrm{pN} 0$ disease versus $\mathrm{pN} 1$ disease. ${ }^{2,3,5}$ More detailed information on the first recur- 
Table III. First sites of distant metastasis according to histologic type

\begin{tabular}{|c|c|c|c|c|}
\hline \multirow[b]{2}{*}{ Site } & \multicolumn{2}{|c|}{ Squamous cell } & \multicolumn{2}{|c|}{ Nonsquamous cell } \\
\hline & pNO disease & $p N 2$ disease & pNO disease & $p N 2$ disease \\
\hline Brain & $4(21.0 \%)$ & $0(0 \%)$ & $16(48.5 \%)$ & $6(19.4 \%)$ \\
\hline Lung & $5(26.3 \%)$ & $4(44.4 \%)$ & $5(15.1 \%)$ & $8(25.8 \%)$ \\
\hline Bone & $4(21.0 \%)$ & $2(22.2 \%)$ & $8(24.2 \%)$ & $10(32.2 \%)$ \\
\hline Liver & $0(0 \%)$ & $1(11.1 \%)$ & $2(6.1 \%)$ & $2(6.4 \%)$ \\
\hline Others & $6(31.6 \%)$ & $2(22.2 \%)$ & $2(6.1 \%)$ & $5(16.1 \%)$ \\
\hline Total & $\overline{19}$ & 9 & 33 & 31 \\
\hline
\end{tabular}

Parentheses indicate percentages of the total number of recurrences.

rence site according to the pathologic nodal status would be useful for both a better pathophysiologic understanding of metastasis and a more efficient postoperative follow-up.

In previous studies by others, $2,3,5$ postoperative recurrence in the ipsilateral lung or even in the contralateral lung used to be classified as intrathoracic local failures. However, in view of the pathophysiologic analysis and selection of treatment modality, pulmonary lesions appearing after surgery should be differentiated into hematogenous distant metastasis, locoregional recurrence at the surgical margin, or second primary carcinoma. Thus in this study ipsilateral pulmonary lesions including the surgical margin were diagnosed as local recurrence. Furthermore, so that second primary cancer could be excluded, pulmonary metastasis as a hematogenous distant tumor was defined to be only multiple growing nodules in the lungs. The first recurrence site to some extent depends on the radicalness of the operation. Recurrence at the surgical margin is more frequent in limited operations such as wedge resection or segmentectomy than lobectomy or pneumonectomy. ${ }^{6}$ Pulmonary resection without total dissection of the hilar-mediastinal lymph nodes might also result in a frequent locoregional recurrence. In fact, locoregional recurrence has been reported to be more frequent in $\mathrm{pN} 1$ disease than in $\mathrm{pN} 0$ disease. ${ }^{3,5}$ This phenomenon might be due to an incomplete dissection (only sampling) of the regional lymph node system. To exclude any bias caused by surgical maneuvers, the present study included only the patients who had undergone either a lobectomy or a pneumonectomy with a total dissection of the ipsilateral hilar-mediastinal lymph nodes. Similar to our previous report, ${ }^{7}$ the ratio of distant metastasis to local recurrence was not different between those with pNO disease and those with pN2 disease.

From an anatomic aspect, the lungs would be unlikely to be the first site of hematogenous metastasis in patients with pN0 disease. On the other hand, pulmonary metastasis might be prevalent in patients with $\mathrm{pN} 2$ disease because of the presence of drainage routes from the $\mathrm{N} 2$ nodes into the superior vena cava, which in turn leads to pulmonary circulation. In fact, the present study showed that pulmonary metastasis was indeed more prevalent in patients with $\mathrm{pN} 2$ disease than in those with pN0 disease and might thus support the aforementioned hypothesis. In addition, we recently reported that the survival of patients with hilar (Nos. 10 and 11) N1 disease was significantly worse than that of patients with lobar (Nos. 12 and 13) N1 disease and that in the pattern of distant metastasis, the former seemed to be similar to N2 disease whereas the latter seemed to be similar to N0 disease. $^{8}$

When a new lesion develops postoperatively in the lungs, our results imply that pulmonary metastasis is most likely suspected in patients with $\mathrm{pN} 2$ disease and a second primary cancer in patients with pN0 disease. To further confirm the present results, we are now prospectively following up patients in whom complete resection was done by the periodic performance of a whole-body computed tomographic scan and bone scintiscan (once every 6 months).

We thank Dr. Brian T. Quinn, Kyushu University, for his critical review and Yumiko Ohshima and Yuko Ishibashi for their expert help in the preparation of this manuscript.

\section{REFERENCES}

1. Kotlyarov EV, Rukosuyev AA. Long-term results and patterns of disease recurrence after radical operations for lung cancer. J Thorac Cardiovasc Surg 1991;102:24-8.

2. Feld R, Rubinstein LV, Weisenberger TH, the Lung Cancer Study Group. Sites of recurrence in resected stage I non-small-cell lung cancer: a guide for future studies. J Clin Oncol 1984;2:1352-8.

3. The Ludwig Lung Cancer Study Group. Patterns of failure in patients with resected stage I and II non-small-cell carcinoma of the lung. Ann Surg 1987;205:67-71. 
4. Mountain $\mathrm{CF}$. A new international staging system for lung cancer. Chest 1986;89(Suppl):225S-33S.

5. Immerman SC, Vanecko RM, Fry WA, Head LR, Shields TW. Site of recurrence in patients with stage I and II carcinoma of the lung resected for cure. Ann Thorac Surg 1981;32:23-7.

6. Ginsberg RJ, Rubinstein L, the Lung Cancer Study Group. Patients with T1 N0 non-SCLC lung cancer [Abstract]. Lung Cancer 1991;7(suppl):83.
7. Yano T, Hara N, Ichinose $Y$, et al. Local recurrence after complete resection for non-small-cell carcinoma of the lung: significance of local control by radiation treatment. J THORaC Cardiovasc Surg 1994;107:8-12.

8. Yano T, Yokoyama H, Inoue T, Asoh H, Tayama K, Ichinose $Y$. Surgical results and prognostic factors of pathologic N1 disease in non-small-cell carcinoma of the lung-significance of N1 level: lobar or hilar nodes. J THORAC CARDIOVASC SURG 1994;107:1398-1402.

\section{Bound volumes available to subscribers}

Bound volumes of THE JOURNAL OF THORACIC AND CARDIOVASCULAR SURGERY are available to subscribers (only) for the 1994 issues from the Publisher, at a cost of $\$ 82.50$ for domestic, $\$ 106.28$ for Canadian, and $\$ 100.50$ for international subscribers for Vol. 107 (January-June) and Vol. 108 (July-December). Shipping charges are included. Each bound volume contains a subject and author index and all advertising is removed. Copies are shipped within 60 days after publication of the last issue of the volume. The binding is durable buckram with the JOURNAL name, volume number, and year stamped in gold on the spine. Payment must accompany all orders. Contact Mosby-Year Book, Inc., Subscription Services, 11830 Westline Industrial Drive, St. Louis, Missouri 63146-3318, USA; phone 1 (800) 4534351 or (314) 453-4351.

Subscriptions must be in force to qualify. Bound volumes are not available in place of a regular JouRNAL subscription. 